\title{
Enquanto este novo trem atravessa o litoral central: Platinidad, poéticas do deslocamento e (des) construção identitária na canção popular urbana de Campo Grande, MS
}

Alvaro Neder ${ }^{*}$

A suposta "identidade cultural" do MS é definida na atualidade por meio de símbolos rurais como a música "regional" e o Pantanal. Entretanto, constata-se que, ao contrário, ambos eram, há poucas décadas, recusados como traços identificatórios pela maior parte da população. Procedeu-se, então, a esta investigação etnomusicológica, utilizando-se o método etnográfico e análise de canções. Como resultados, verificou-se que estamos frente a um complexo e contraditório processo de "invenção de uma tradição", que, entretanto, teve efetividade material na construção de oposições críticas ao status quo.

Palavras- chave: música regional; etnomusicologia; pós-estruturalismo

Mato Grosso do Sul's alleged "cultural identity" is currently defined through rural symbols,

\section{Introdução}

N o dia 23 de Setembro de 2006, o 1 serviço de notícias via internet MS Notícias, sob o título "No próximo domingo, show reúne três gerações da música no MS", faz a seguinte observação: "Nomes como Geraldo Roca e Paulo Simões, autores de 'Trem do Pantanal', música que é considerada o hino do Mato Grosso do Sul, também são destaques do show..." .

Efetivamente, esta canção, e outras do movimento nomeado pelo jor-

\footnotetext{
* Mestre em Educação pela UFMS. Doutor em Música. Instituto Federal de Educação, Ciência e Tecnologia do Rio de Janeiro / IFRJ.alvaroneder@ig.com.br

${ }^{1}$ MS Notícias. "No próximo domingo, show reúne três gerações da música de MS". ARRUDA, Josemil. Campo Frande, 23.09.2006. Disponível em: <http://www.msnoticias.com. $\mathrm{br} / \mathrm{p}=$ ler\&ide $=204918>$. Acesso em: 23.09.2006.
} 
such as "regional" music and the Pantanal. On the contrary, however, both elements were, just few decades ago, refused as identificatory traces by the largest part of the population. Such problem prompted this ethnomusicologic investigation, which used the ethnographic method and song analysis. As results, it was discovered that we are witnessing a complex and contradictory process of "tradition invention", which, notwithstanding, had material effectivity in the construction of critical oppositions to the status quo.

Key words: regional music; ethnomusicology; post-structuralism

nalista e pesquisador musical José Octávio Guizzo como moderna música popular urbana do $\mathrm{MS}^{1}$, são, na atualidade, geralmente aceitas como representativas da identidade ${ }^{2}$ cultural do estado. Entretanto, ao contrário, poucas décadas antes era uma música vista como "dos malucos" da cidade, relacionada à contracultura e à contestação. Como uma música marginal, em pouco tempo, se torna o "hino do MS"?

Este momento de desinteresse foi retido pela memória da professora Maria da Glória Sá Rosa, pesquisadora da música campo-grandense, quando, em artigo em que historia a moderna música urbana do estado, lembra: "Houve época em que (...) os compositores eram ironizados por uma população voltada somente

${ }^{1}$ GUIZZO, José Octávio. A moderna música popular urbana de Mato Grosso do Sul. Campo Grande: EdUFMS, 1982, p. 5.

${ }^{2} \mathrm{O}$ termo "identidade", que será muitas vezes empregado, tem sido usado de diversas e conflitantes maneiras, muitas das quais associadas ao essencialismo e/ou ao regionalismo, sendo, portanto, necessário conceituá-lo de imediato com o sentido que será utilizado aqui. Etimologicamente, "identidade" deriva do latim identitas, provavelmente uma fusão de idem, "o mesmo", e entitas, "entidade" (Identidade, 1997). Como tal, em uma perspectiva pós-estruturalista, como a adotada neste trabalho, o termo "identidade" exprime um conceito errôneo, pois um sujeito dividido (entre um efeito de consciência, provocado pelo discurso, e seu inconsciente) não poderia, em qualquer circunstância, ser idêntico a si próprio. Entretanto, o termo é utilizado mesmo assim, em virtude de sua ampla aceitação em volumosa e importante bibliografia nas ciências sociais e humanidades. Para o pós-estruturalismo, o conceito mais adequado às vicissitudes da produção (sempre precária, não essencial, problemática e descentrada) do sujeito seria "subjetividade". Isso porque este coletivo teórico tende a compreender o que se chama de "identidade" como um conjunto de diferentes "posições subjetivas" assumidas temporariamente pelo sujeito ao ativá-las por intermédio do discurso - inclusive os discursos verbais e musicais veiculados pelas canções. Portanto, ao conceito estático de "identidade" é preferida uma política de representação, que permite a contínua desestabilização da ideologia dominante por intermédio de práticas de intervenção ativa dos sujeitos e grupos não-hegemônicos sobre as modalidades de representação, neste caso, com destaque para a canção. 
para o lucro ...”’3. Esta marginalidade é confirmada também pelos próprios compositores do movimento e campo-grandenses que viveram nessa época, como atestam os diversos depoimentos colhidos para este trabalho.

Em vista disso, a naturalidade com que tais relatos atribuem à população do MS em geral o sentido identificatório veiculado por uma canção contracultural, celebratória dos alternativos hábitos vagamundos dos mochileiros, e enaltecedora de elementos humanos e culturais atribuídos pelas elites ao atraso (o paraguaio, o boliviano, o caipira, o índio) não deixa de causar espécie. Procurando oferecer uma contribuição para a compreensão deste enigma, produzi uma segunda tese de doutorado ${ }^{4}$, cujos resultados são parcialmente divulgados aqui.

O movimento em questão teve início no final dos anos 60 e pleno desenvolvimento nos anos 70, chegando ao auge de sua popularidade nos anos $80 \mathrm{e}$ sendo atuante até o momento, quando, inclusive, é apropriado pelas gerações mais jovens. Nunca articulado como tal por meio de manifestos, organizou-se de maneira flexível em torno dos compositores Geraldo Espíndola, Paulo Simões e Geraldo Roca, cuja produção se insere na formação discursiva analisada aqui. Propostas importantes e individualizadas, como as do Grupo Acaba, desde o princípio esforçaram-se por diferenciar-se das já diversas concepções musicais e culturais dos três compositores, mas não chegaram a constituir um movimento à parte e mantiveram-se envolvidas na mesma categoria, instrumentalizada sempre que projetos individuais ou coletivos e séries de shows e gravações são implementados.

Dada a diversidade que caracteriza o movimento, poderia se pensar que, talvez, o único traço comum entre todos os seus participantes pudesse ser a tematização de Mato Grosso do Sul em suas letras e/ou por intermédio do emprego de gêneros musicais ou instrumentos aí encontrados. No entanto, há uma quantidade de canções importantes neste repertório que não utilizam qualquer

\footnotetext{
${ }^{3}$ ROSA, Maria da Gloria Sá. Música, signo revelador de uma cdiade. In: MEDEIROS, L. P., CUNHA, M. L. (Orgs.). Campo Grande - 100 anos de construção. Campo Grande: Matriz Ed., 1999, p. 221.

${ }^{4}$ NEDER, Alvaro S. C. "Enquanto este novo trem atravessa o Litoral Central”: platinidad, poéticas do deslocamento e (des)construção identitária na canção popular urbana de Campo Grande, Mato Grosso do Sul. 2011. Tese (Doutorado em Música) - Programa de Pós-graduação em Música, Centro de Letras e Artes, Universidade Federal do Estado do Rio de Janeiro.
} 
traço regional reconhecível - caso de, por exemplo, "Uma pra estrada" (Geraldo Roca), "Mochileira” (Geraldo Roca), “Abril” (Celito Espíndola e Antonio Porto), "Vida bela vida" (Guilherme Rondon e Paulo Simões) e muitas outras. Sendo assim, desde o início, este movimento se caracteriza por sua ausência de unidade estética, estilística e ideológica. Coloca-se, portanto, em conflito com a ideia de "identidade", e solicita, ao contrário, uma investigação sobre seu papel na desconstrução de identidades.

Embora a referida denominação cunhada por Guizzo seja mencionada ocasionalmente, principalmente na imprensa escrita e livros, há várias outras e pouco consenso quanto a seu uso. Entretanto, o título genérico de "música regional" ganhou, com o tempo, larga aceitação, sendo amplamente utilizado. O nome chama a atenção, pois o mais superficial exame dessa música evidencia tensões entre elementos regionais, ideologias nacionalistas e gêneros transnacionais articulados por intermédio da globalização capitalista.

Uma primeira indicação para as possíveis razões do rótulo "música regional" são as ligações entre essa música e a atividade pecuária. Conforme discutiremos, são fortes as relações ideológicas entre essa música nascida em um estado agrário e a configuração das forças produtivas nesse mesmo estado. A base econômica pecuária que constituiu e constitui esta unidade federativa será estudada como um dado, visto que qualquer elemento, cultural ou outro, aí encontrado, não pode ser sequer pensado sem levá-la em consideração - mesmo que a ela se oponha.

Entender a configuração própria que assume a atividade pecuária no sul do antigo Mato Grosso pressupõe compreender a intensa busca por desenvolvimento tecnológico e econômico liderada pelos fazendeiros. A pecuária, nessa parte do estado, orientou-se desde cedo para a busca de inovações que dinamizassem a economia local, no que foi extremamente bem sucedida. Promovendo o melhoramento genético de seus rebanhos e investindo em sua nutrição, os pecuaristas aumentaram o efetivo de bovinos do estado para a cifra de 22.325.663 cabeças, colocando-o em terceiro lugar entre as unidades da federação, com a participação de $10,9 \%$ no quantitativo nacional - dados de $2009^{5}$.

\footnotetext{
${ }^{5}$ IBGE. Efetivo de bovinos em 31.12 e participações relativa e acumulada no efetivo total, segundo as Unidades da Federação e os 20 municípios com os maiores efetivos em ordem decrescente2009. Disponível em: <http://www.ibge.gov/home/estatistica/economia/ppm/tabelas_pdf/ tb10.pdf> Acesso em: 14 jul. 2011.
} 
A pecuária constituiu-se, assim, no sustentáculo da modernização capitalista na região. Ao contrário, as forças urbanas do século 19, os grandes comerciantes de Cuiabá e Corumbá, que eram ligados ao capital financeiro internacional, passado um período de predominância e forte exploração ao pecuarista, tornaram-se decadentes na segunda década do século $20^{6}$. O novo comércio que passou a existir em Campo Grande, concomitante à gradativa transformação dessa pequena vila em centro político e econômico após 1914, permaneceu, por algumas décadas, inteiramente dependente da atividade pecuária. Com o controle das forças produtivas mantido pelos pecuaristas, a ênfase na modernização, proposta por eles, influenciou decisivamente a ideologia da cidade de Campo Grande, escolhida como sede para as articulações dessa classe.

Esta peculiar configuração local assumida pelas forças produtivas do campo e da cidade deve ser mantida em mente, pois há, portanto, forte relação entre a orientação modernizante dos pecuaristas, a ideologia desenvolvimentista da cidade de Campo Grande e a própria busca, por parte dos compositores e músicos aqui em foco, de manterem-se atualizados com relação às últimas tendências culturais internacionais e nacionais. Haverá, no entanto, contradições entre a base econômica e política pecuarista e os profissionais liberais e comerciantes de Campo Grande. Não poderia deixar de haver, também, contradições entre pecuaristas e compositores.

Esta cidade, que, desde o início do século 20, produziu uma economia em que cada vez mais predominou o setor de serviços, inicialmente estava voltada inteiramente para o atendimento das necessidades do campo e das fazendas. Gradualmente, no entanto, começou a desenvolver um potencial de produção e consumo próprios que lhe propiciaria certa autonomia com relação ao interior e ao mundo agrário. Surgiu, então, desses profissionais liberais, comerciantes e funcionários públicos, um projeto de urbanização, atualização técnica e modernização produtiva e cultural voltado para Campo Grande que seria parcialmente dissonante em relação às necessidades dos pecuaristas. Como parte da classe média urbana, sendo ideologicamente identificados a estes setores de serviços, os compositores também manifestariam em suas canções estas contradições em

\footnotetext{
${ }^{6}$ ALVES, Gilberto Luiz. A casa commercial e o capital financeiro em Mato Grosso: 1870 - 1929. Campo Grande: EdUNIDERP, 2005, p. 30.
} 
relação aos fazendeiros. Tais conflitos ficam expressos, entre outras canções, em "Polca outra vez", de Geraldo Roca.

Além da economia, a música e cultura de Campo Grande, das quais é ponta de lança a música de que estamos tratando, diferem sobremaneira daquelas do restante do estado. Basicamente, Campo Grande adota um perfil mais urbano, cosmopolita e tecnologizado, alinhado com sua situação de centro decisório, onde residem tanto os empresários rurais detentores de propriedades localizadas no restante do estado quanto os profissionais liberais, funcionários e comerciantes urbanos. Estes, a um só tempo necessitam das receitas geradas pela agropecuária - muitas vezes até estão vinculados às oligarquias rurais por parentesco - e manifestam ambiguidade frente à sua estruturação social e ideológica. A cidade usufrui da economia agrária do interior, mas não se envolve diretamente com ela, assumindo a função de fornecedora de produtos e serviços, com destaque para o comércio. Como resultado desses conflitos entre os setores urbanos e agrários, a participação da agropecuária no Produto Interno Bruto [PIB] do estado vem decrescendo: de 46,7\% em 1980, passou a 16,6\% em 2008, principalmente devido ao crescimento da participação dos serviços ${ }^{7}$. No entanto, estes setores de serviços estão desproporcionalmente concentrados na capital. Já o interior possui uma realidade fortemente agrária, o que transparece em suas preferências culturais.

Esta realidade dicotômica propiciou uma busca de distinção e atualização cultural, por parte da cidade de Campo Grande, baseada, desde a segunda década do século 20, na importação de modelos de fora - exatamente a maneira como os pecuaristas procuraram modernizar sua atividade. Tal busca de atualização expressa, portanto, a ideologia modernizante dos pecuaristas, bem como consensos parciais e certa interdependência obtidos entre esta classe e os setores urbanos. Músicas de sucesso nas grandes capitais nacionais e internacionais chegavam

\footnotetext{
${ }^{7}$ SUPLAN/SECRETARIA DE ESTADO DE FINANÇAS, ORÇAMENTO E PLANEJAMENTO (Campo Grande, MS). Produto Interno Bruto - PIB/MS, 1980/97 (mimeo), [199-]; IBGE. Tabela 7 - Participação das atividades econômicas no valor adicionado bruto a preços básicos, por Unidades da Federação - 2004 -2008. Disponível em : <http://www.ibge.gov.br/home/estatistica/ economia/contasregionais/2008/tabelas_pdf/tab07.pdf > . Acesso em: 19 nov 2011; IBGE. Tabela 7. Participação das atividades econômicas no valor adicionado bruto a preços básicos, por Unidades da Federação - 1995-2008. Disponível em: ftp://ftp.ibge.gov.br/Contas_Regionais/2008/tab07_retropolacao.zip. Acesso em: 19 nov. 2011.
} 
pelo rádio, e cantores e orquestras famosos eram trazidos por iniciativa de um clube da elite local, o Rádio Clube, que muito investiu na atualização cultural do campo-grandense. À medida que a cidade crescia, novos clubes, emissoras de rádio e TV aumentaram essa oferta de produtos importados.

A dicotomia mundo rural versus mundo "desenvolvido", que se projetava sobre a dicotomia capital versus interior era, assim, mapeada a partir dos gêneros musicais em voga nos bailes de Campo Grande. Nesses bailes, especialmente no Rádio Clube, mas não apenas nele, era esperado que a programação constasse de gêneros da moda buscados nas capitais brasileiras e internacionais, sendo executados com toda a competência por músicos locais ou trazidos de fora especialmente para a ocasião. No entanto, por volta de meia-noite, quando a animação estava no auge, desencadeavam-se indefectivelmente as animadas polcas paraguaias. Referidas como "limpa-banco" devido ao furor dançarino que suscitavam, as polcas sempre fizeram muito sucesso, impelindo todos ao salão. Fossem bailes de carnaval, de réveillon ou qualquer outra ocasião durante o ano. Portanto, como verdadeira tradução da ideologia dominante, que opunha o rural ao cosmopolita, capital e interior, nos bailes não havia mistura entre as músicas "da capital" e "do interior". Ocupavam elas seções claramente delimitadas da vida social.

Devido a toda essa ênfase no cosmopolitismo e no desenvolvimentismo, entendidos como necessidades locais históricas do desenvolvimento capitalista, liderado pela economia agrária - especialmente pecuária -, a ênfase recente na ideia de regionalismo surge como interrogação. Para os três compositores iniciais do movimento, o rock e a contracultura - recebidos pela via midiática - foram influências fundamentais, o que coloca em primeiro plano a ênfase nos fluxos globais, econômicos e culturais. Há, inclusive, depoimentos, em que criticam explicitamente a noção de regionalismo (Simões: "Algumas músicas (...) que tentavam denunciar a situação envolvendo o planeta inteiro e não só um estilo regional de criação era o que nos interessava!”; Geraldo Espíndola: "Eu acho que regional é coisa pra jornalista catalogar"s.

\footnotetext{
${ }^{8}$ Apud SIMÕES [CORRÊA FILHO], Paulo (Coord.). Raízes da música em Mato Grosso do Sul. Entrevistas com compositores. Realização inédita da Universidade Federal de Mato Grosso do Sul. Entrevistas realizadas em 1984. [Campo Grande]: [s.n.], [1984?]. Cópia datilografada, não paginada.
} 
O regionalismo, portanto, não era reclamado, inicialmente, pelos participantes do movimento. Na verdade, passa gradualmente a ser aceito à medida que se estabelece a divisão do estado, em 1977. Sendo assim, torna-se significativo em si mesmo: o que pretenderia definir, conciliar, defender ou orquestrar? Não seria plausível ver uma relação entre este regionalismo reclamado e o movimento divisionista? E, caso existente, o que significaria essa relação? E qual seria o papel dessa música nesse processo?

O tema do divisionismo merece atenção concentrada, devido à sua importância para esta música e cultura. Causa centenária no sul do antigo Mato Grosso, o divisionismo se apoiou justamente em um regionalismo exacerbado, que visava defender e justificar a ideia de separação "do norte" enumerando as diferenças entre as duas regiões e salientando as singularidades do sul. Conforme argumenta a historiadora Marisa $\operatorname{Bittar}^{10}$, a divisão se apresenta como uma articulação das elites agrárias sulistas visando reter o poder político e econômico sobre o sul por meio da transformação dessa região em um estado independente.

No entanto, apesar de estratégico para o projeto de poder dos proprietários de terras, o regionalismo, com seu caráter estático, vai de encontro ao dinamismo da ideologia desenvolvimentista desses mesmos proprietários. Por supor possível narrar a realidade local sem se reportar ao estágio de desenvolvimento do capitalismo global, o regionalismo entra em contradição com a necessidade da atividade pecuária em manter-se atualizada com as últimas inovações técnicas e tecnológicas. Ao contrário, é necessário, para o progresso dessa atividade, reportar-se continuamente ao mercado global, que é também a instância que adquire sua mercadoria. Sendo assim, a questão da "música regional" se insere no interior - e expressa a tensão - de um amplo processo contraditório, cuja análise e interpretação são justamente o objetivo principal deste $\operatorname{artigo}{ }^{11}$.

\footnotetext{
${ }^{9} \mathrm{O}$ antigo estado do Mato Grosso uno era composto, na verdade, de três regiões bastante distintas em seus aspectos: o sul, ocupado pelo atual Mato Grosso do Sul, o norte, com características derivadas de sua proximidade com a floresta amazônica, e o centro, ocupado pela capital Cuiabá. No entanto, Cuiabá terminou por ser referida como o "norte", como consequência da polarização divisionista que a opôs ao sul, dominado historicamente por Campo Grande.
}

${ }^{10}$ BITTAR, Marisa. Mato Grosso do Sul: a construção de um estado. Regionalismo e divisionismo no sul de Mato Grosso. Volumes 1 e 2. Campo Grande: UFMS, 2009;

${ }^{11}$ A contradição é compreendida, aqui, a partir da matriz psicanalítica, como fruto do embate entre pulsões destruidoras e criativas, inerentes aos sujeitos inseridos na cultura, e, a partir da teoria 
Adicionando-se entre as múltiplas contradições já apontadas até aqui, o advento dessa "música regional" - termo que, como vimos, interessa às elites pecuaristas para consolidação de sua hegemonia após a divisão - se deu na década de 1960, marcada por momentos históricos críticos ocorridos no estado. Nestes momentos, as populações do então Mato Grosso manifestaram sua rejeição aos grandes proprietários rurais e pecuaristas, tradicionais comandantes da política estadual, bem como à ditadura. Tal rejeição trouxe vitórias expressivas para a oposição, nas eleições de 1965, 1966, 1974, 1978, 1982, 1996 e 1998.

Em 1965, pouco tempo antes do surgimento da "música regional", o político sulista Pedro Pedrossian (PSD) foi eleito governador do estado, concorrendo com o tradicional fazendeiro Lúdio Martins Coelho (UDN), candidato do regime militar. Desde o início de sua campanha, Pedrossian, um engenheiro de origem humilde, se voltava contra "as oligarquias e estruturas feudais que sempre dominaram Mato Grosso"12, e contou com o apoio da esquerda, do PTB e dos ferroviários do estado - ou seja, parte dos setores urbanos. Esta campanha se insere num período, que se estende dos anos 1960 aos 1970, caracterizado por uma grande efervescência cultural em Campo Grande. Tal efervescência caracterizou-se pela criação da universidade estadual (depois federal, UFMS), faculdades e festivais de música e teatro afinados com os movimentos estudantis de oposição à ditadura no Rio de Janeiro e São Paulo. É de se notar que os envolvidos nesses festivais fossem, justamente, os profissionais liberais, funcionários e comerciantes

marxista, como o que poderia levar a uma transformação do modo de produção. Justifica-se, assim, o esforço analítico em não tentar resolver as contradições, testemunhando-se, ao contrário, sua proliferação. Pressupõe-se, neste trabalho, que as práticas culturais tornam-se tão mais transformadoras quanto mais contraditórias sejam. Se for assim, a medida de seu potencial transformador é a quantidade de pessoas que envolvem, e a capacidade dessas práticas de gerar polêmica e debate entre as pessoas envolvidas. Desta maneira, embora seja inegável que o movimento musical aqui estudado não expresse as lutas dos setores mais oprimidos da população sul-mato-grossense, exprimindo os dilemas das classes médias diante das articulações dos setores dominantes em torno de um projeto de poder regional e nacional, seus significados não se esgotam aí. Isso porque seu estudo evidencia, justamente, a contradição entre diferentes projetos: se é identificável tal articulação de setores dominantes do estado, a ela se superpõem inúmeras outras polêmicas, envolvendo a inclusão de saberes tradicionais, a preocupação com etnias indígenas, a integração da América Latina com o questionamento da hegemonia econômica, política e cultural dos grandes centros brasileiros, e, a partir do ideário da Nova Esquerda e dos Estudos Culturais, a reformulação dos papéis sociais das mulheres e dos homens, dos costumes e dos usos dos corpos - polêmicas que abrangem virtualmente todas as classes sociais.

${ }^{12}$ Pedro Pedrossian, apud BITTAR, Marisa. Op. cit., volume 2, p. 98. 
da cidade de Campo Grande, que são os setores de serviços já descritos como interessados na busca de um caminho singular para a urbanização da cidade, independente das direções impostas pela economia agrária. Foi justamente nesses festivais - mais precisamente na segunda edição, em 1968 - que nasceu a música aqui estudada, a partir da atuação conjunta de Paulo Simões e Geraldo Espíndola. Foi por esta época em que começam a compor juntos, adicionando, logo depois, Geraldo Roca e outros a seu círculo.

Talvez não fosse por coincidência que a referida dicotomia ideológica entre capital e interior, mapeada a partir dos discursos musicais nos bailes de Campo Grande, continuaria a se verificar no I Festival, que ocorreu em 1967. Este evento colocou lado a lado, sem uma mútua contaminação que trouxesse consequências imediatas para a produção local, a canção regionalista "Mané Bento, vaqueiro do Pantanal" (Paulo Mendonça de Souza/ José Otávio Guizzo) e cópias de canções metropolitanas. No entanto, "Mané Bento" desencadeava um processo de grande importância: o desrecalque da realidade rural, reprimida pela sociedade de Campo Grande em sua busca de modernização. O choque causado pela pioneira canção regionalista e a percepção de que as elites urbanas buscavam se dissociar das referências a Mato Grosso, ao Pantanal e à vida no campo, em geral, ficam expressas no comentário de Simões:

No Festival de 67 surpreendeu-me a música vencedora - "Mané Bento, vaqueiro do Pantanal - (...), pois através dela, pela primeira vez me ocorreu que eu estava em Mato Grosso e que Mato Grosso poderia ser tema de música! O que mais me impressionou foi uma música falando de Pantanal ser apresentada com toda pompa à elite campo-grandense. ${ }^{13}$

Mesmo com o dado fundamental representado pelo rompimento do silêncio com relação à realidade rural do estado em uma produção cultural apresentada às elites urbanas, passado e presente, rural e urbano continuavam a ocupar, assim, partes relativamente estanques da vida social, indicando interditos e segregações. É apenas com a hibridação, em uma mesma produção, do arcaico e do moderno, do campo e da cidade, que se tornaria possível revelar a contradição violenta inerente à superposição destes dois planos no presente da vida urbana contemporânea globalizada. Este seria o achado da música que estamos examinando, apenas a partir do II Festival, ocorrido em 1968.

${ }^{13}$ SIMÕES [CORRÊA FILHO], Paulo (Coord.). Op. cit.. 
Neste sentido, a maior novidade trazida por esta edição do Festival foi representada pelo conjunto Os Bizarros, formado pelos compositores Geraldo Espíndola e Paulo Simões. O grupo mostrava em seus elementos uma entusiástica adesão à Tropicália, começando pelo figurino adotado. A música escolhida, "2001" (Mutantes / Tom Zé), também era oriunda do Festival da Record, "onde causara impacto como uma das primeiras e mais audaciosas tentativas de se chegar a uma síntese rural/ urbana"14. Conforme relata Simões:

E é uma estranha coincidência dessa música eu ter recebido o disco que era a primeira música de todo aquele rolo da Tropicália que tentou fazer uma fusão de até $50 \%$ entre música urbana ou rock e música sertaneja. A música começava com viola caipira, depois eles cantavam um negócio que era meio cateretê e outra metade da música era rock. Isso chamou muito a nossa atenção ${ }^{15}$.

Se "Mané Bento" era uma toada sertaneja que coexistiu com canções de corte metropolitano sem que se constatasse nenhuma influência de parte a parte, percebe-se, com a participação d'Os Bizarros no II Festival, o primeiro passo na busca deliberada de um modelo sul-mato-grossense desta síntese - ou melhor, hibridação - rural/ urbana. Tal hibridação incorporava ao rural até então recalcado a situação contemporânea da cidade, da qual eram aceitas como partes integrantes a indústria cultural, a contracultura e as questões cruciais então para o jovem, tanto no plano nacional como no transnacional, em oposição a uma música regionalista.

Portanto, esta música é uma manifestação que surge de um momento crítico (pouco depois da vitória da oposição na eleição de 1965, em pleno período de efervescência cultural em Campo Grande). Este momento se caracteriza tanto pela busca, por parte das populações locais, de um caminho para a modernização de Campo Grande que fosse independente das estruturas sociais agrárias, quanto pela atitude de desrecalque em relação à situação periférica ocupada pela cidade, num estado rural e interiorano, junto a países platinos. Isto se percebe, também, a partir do fato de que o movimento divisionista, nesta época, encontrava-se desativado e incapaz de motivar a população. A nova música urbana manteria esta

\footnotetext{
${ }^{14}$ FONSECA, Candido Alberto da, SIMÕES, Paulo. Os festivais de música no sul de Mato Grosso (1967- 1981. In: ROSA, Maria da Glória Sá (Coord.). Festivais de música em Mato Grosso do Sul. Campo Grande: EdUFMS, 1981, p. 17.
}

${ }^{15}$ SIMÕES [CORRÊA FILHO], Paulo (Coord.). Op. cit. 
marca crítica, que foi importante para afirmar "Trem do Pantanal" como hino de Mato Grosso do Sul. As mudanças sociais e econômicas reveladas por este processo de afirmação possibilitam, então, uma análise do papel ativo dessa música na construção e transformação do capital.

Sintetizando, seria possível dizer que, apesar de organizada pelas classes médias em gravitação na órbita de influência de uma burguesia agrária hegemônica, essa música evidencia uma polifonia de vozes, muitas delas críticas. Percebe-se tal polifonia desde a instância da produção: não há qualquer possibilidade de atribuir uma ideologia nativista a este movimento musical como um todo. Seus compositores e intérpretes assumem diferentes posições subjetivas ao se relacionarem com o material regionalista. Tais posições se estendem do elogio sentimental e melancólico à crítica irônica, passando pela relativização do regional pela via do nacional e mesmo da problematização da ideia de um projeto nacional, principalmente por meio do rock e das músicas paraguaia, boliviana e argentina. Estas posições produzidas pelo movimento aqui estudado participam da construção de subjetividades críticas por meio de suas canções e das polêmicas veiculadas por elas (já mencionadas). Tal dinâmica confere à canção um papel multiplicador que lhe confere eficácia no plano material.

O questionamento à identidade "regional" e mesmo nacional se verifica, por exemplo, pelo nome proposto por Geraldo Roca em um de seus CDs ${ }^{16}$, Música do Litoral Central, que parece bastante estimulante. Ele enfeixa alguns temas fundamentais dessa música, tal como a compreendo. Em primeiro lugar, esse provocativo "litoral central" a que Roca se refere deriva da chamada "música litoraleña argentina", música da região conhecida como "litoral argentino", ou seja, a bacia do rio da Prata. Esta bacia possui importância primordial para o estado, pois, em situação de isolamento, era por seus rios que recebia mantimentos, fazia comércio e intercâmbios culturais. Tal situação se manteve até 1914, quando a Estrada de Ferro Noroeste do Brasil chega a Campo Grande, produzindo uma alteração radical na posição política e econômica dessa cidade e dos pecuaristas no balanço de forças regional.

Os profundos e prolongados intercâmbios possibilitados pela bacia do rio da Prata se davam, em grande parte, entre os vários países e regiões latino-ame-

\footnotetext{
${ }^{16}$ ROCA, Geraldo. Música do Litoral Central. 1 CD. Produção independente, 1997.
} 
ricanos banhados por ela. Isso levou à formação da chamada América Platina ${ }^{17}$, unidade cultural que envolve desde o MS, o oeste do Paraná, o oeste de Santa Catarina, Rio Grande do Sul, Uruguai, Argentina e Paraguai. O enorme território da América Platina situado dentro do Brasil se diferencia e se opõe ao Brasil entendido como Estado-Nação, supostamente delimitado de maneira clara com relação a seus vizinhos sul-americanos, o que, a meu ver, coloca problemas ao projeto de unidade nacional.

Assim, a Música do Litoral Central merece ser estudada, entre outras coisas, enquanto busca de direções que orientassem um processo de urbanização, pensado a partir de uma posição periférica, marcada pelo isolamento no interior da América Platina. Essa proposição e seus impasses interferiram num debate que envolveu o comércio, a arquitetura, a medicina, enfim, todos os setores de serviços de Campo Grande, empenhados, em certo momento histórico, numa procura de superação das estruturas sociais produzidas pela economia agrária, o que ocorreu, como demonstram os números do PIB. A Música do Litoral Central contribuiu ativamente para essa efetiva transformação. O litoral central, então, implicita complexas relações entre o local, o nacional, o sul-americano e o global, que passamos a discutir.

Tais relações são de constante tensão entre o Estado nacional brasileiro e o local sul-mato-grossense, considerando que esta região "onde o Brasil foi Paraguai" ("Sonhos guaranis”, de Almir Sater e Paulo Simões) há muito inspira preocupações nacionalistas de cunho geopolítico. Desde Mário Travassos, em sua influente e seminal obra Projeção continental do Brasil (1938) ${ }^{18}$, se encontra formalizada uma inquietação com o Oeste brasileiro, que, em virtude de sua posição limítrofe a outros países, poderia se tornar presa deles. A Constituinte brasileira de 1934, por sua vez, concedeu bastante atenção às fronteiras internacionais, assim como o Estado Novo varguista, que, justamente motivado por tais preocupações com a segurança nacional, instituiu o Território Federal de Ponta Porã em 1943, na divisa do sul do estado com o Paraguai. Já José de Melo e Silva alertava veementemente em sua obra Fronteiras Guaranis, de 1939, contra o que denominou o perigo da "guaranização" da população de fronteira, e sugeria

${ }^{17}$ Cf. ALVES, Gilberto Luiz. Depoimento pessoal concedido ao autor. 26 jan. 2009.

${ }^{18}$ TRAVASSOS, Mario. Projeção continental do Brasil. São Paulo: Nacional, 1938. 
providências urgentes ${ }^{19}$. Cearense que se estabeleceu em Bela Vista, fronteira do então Mato Grosso com o Paraguai, no ano de 1932, para exercer o cargo de juiz de direito, Melo e Silva se tornou importante cronista da vida na fronteira sulista, sendo autor de obras consultadas com interesse pela historiografia contemporânea do estado.

A seguir, a questão passa a ser matéria de estudos da Escola Superior de Guerra, tornando-se estratégica para a ditadura militar implantada em 1964, o que levaria, finalmente, à divisão do $\operatorname{estado}^{20}$. Assim, ao fazer o elogio da cultura latino-americana, em geral, e paraguaia, em particular, na constituição do sul-mato-grossense, a Música do Litoral Central entra em contradição com o projeto nacional. No mesmo movimento, problematiza o divisionismo - que, entretanto, apóia, em certas de suas vertentes -, pois este se concretizou, em última análise, justamente por ir ao encontro das teses do estado nacional, encampadas pela ditadura.

Apesar da importância fundamental das trocas materiais e culturais permitidas pelos rios com os países platinos, tais trocas não eram restritas aos vizinhos sul-americanos. Pelo contrário, naquele momento em que o Brasil não era industrializado, grande parte dos bens de consumo e produção era importada de países da Europa, América do Norte e outros continentes. Não apenas aqueles produtos de alta distinção, mas também todos os que se fizessem necessários às populações humildes. Eram famosas, por exemplo, as lâminas alemãs de excelente aço da cidade de Solingen, que atendiam tanto as necessidades dos trabalhadores braçais da agricultura quanto as dos burgueses. O ponto principal, aqui, é a tensão provocada, pela globalização, nos projetos regionalista e nacionalista. Por isso, o Litoral Central é também metáfora da articulação entre o global e o local que preside a Música do Litoral Central desde muito antes de sua concepção, explicitando suas conexões com o avanço do capitalismo planetário e as transformações culturais mundializadas, das lâminas Solingen ao rock'n'roll, passando pelas músicas e culturas latino-americanas.

Processamento criativo de toda essa situação sociocultural, a Música do Litoral Central apresenta caráter nitidamente indeterminado, embora constan-

\footnotetext{
${ }^{19}$ SILVA, José de Melo e. Fronteiras guaranis. 2a. ed. Atualização e notas Hildebrando Campestrini. Campo Grande: IHGMS, [1939], 2003.

${ }^{20}$ BITTAR, Marisa. Op. cit., volume 1, pp. 263-314.
} 
temente em conflito com tendências reificantes. Como parte dos debates travados na cidade de Campo Grande pelos profissionais liberais, funcionários e comerciantes em busca de um caminho singular para a urbanização e o desenvolvimento da cidade, com a adição de preocupações com uma redefinição das lealdades e alianças envolvendo a América Platina e os grandes centros nacionais, vários elementos em suas letras e músicas apontam para essa indeterminação, principalmente a dúvida, a incerteza, o movimento constante, o deslocamento de sentidos.

As canções da MLC surgem repentinamente no interior do Brasil, rompendo com tradições musicais sertanejas de apego à terra e de conformidade ao trabalho na fazenda, seja mandando no empregado, seja a mando do patrão. Enquanto as músicas sertanejas retratavam protagonistas deterministicamente atados ao seu local de origem, a persona poética das canções da MLC é composta de seres em constante fluxo, deslocamento, ausência de pertencimento, inacabamento. Isto é comunicado não apenas por meio das mensagens comunicadas pelas letras de música ou dos recursos retóricos empregados em suas figuras de linguagem, mas também por meio da música: gêneros musicais, estilos de execução e instrumentação, principalmente.

Evidentemente, há uma larga tradição de itinerância na música sertaneja: o eu lírico destas canções é, frequentemente, alguém que está longe de casa, seja em uma comitiva boiadeira, seja trabalhando em uma fazenda distante, seja morando na cidade grande. Note-se, no entanto, que a identidade do trabalhador rural no latifúndio é mantida, mesmo que muitas vezes lamentada. Também a identidade do patrão é preservada nessas canções, sendo frequentemente celebrada.

Já no caso desta vertente de canções da MLC, não se pode afirmar com toda certeza qual é a identidade de seus protagonistas. Os tropos do fluxo e do deslocamento, constantes em letra e música em numerosas produções do movimento, se comunicam metonimicamente ao ethos dos protagonistas, e o resultado é uma subjetividade em processo, nunca determinada. Há, então, uma relação entre esta característica dessas canções e sua atuação desestabilizadora sobre as representações dominantes, pela via do papel multiplicador, já mencionado, da construção de subjetividades críticas. Esta relação se verifica a partir da constatação da importância da MLC nos debates culturais do estado. 
A MLC possui, então, características fundamentais (o deslocamento e a indeterminação) que se articulam a questões históricas, antropológicas e sociológicas da região. Entre elas, destacam-se a procura pela modernização, a situação de identidade nunca definida em meio a fluxos migratórios constantes, o atraso, isolamento, inacabamento e provisoriedade. Relacionando todos estes elementos, desejo inserir aí a metáfora do litoral central, por condensar parte importante dos sentidos e significados veiculados pela música que estamos tratando. Devido a isso, adotaremos a sugestão de Roca, abreviando-a por meio da sigla MLC.

Expressando a realidade periférica do estado junto ao Paraguai e à região platina, a busca por melhores condições de vida pela via da superação da condição agrária e a rejeição à dominância dos fazendeiros, em certo momento a aceitação da MLC aumentou, por parte de setores rurais e urbanos, tanto dominantes como subalternos. Esta situação de gradual adoção da MLC como representação identificatória foi anotada em 1982 por Guizzo:

Trem do Pantanal, composição de [Paulo Simões] e de Geraldo Roca, hoje transformada numa espécie de hino da moderna música popular urbana de Mato Grosso do Sul, possui (...) forte apelo popular e inusitado poder de comunicabilidade. ${ }^{21}$

No entanto, percorreu-se uma grande distância entre a constatação de que a canção é uma "espécie de hino da moderna música popular urbana de Mato Grosso do Sul", e a afirmação de que é "considerada o hino do Mato Grosso do Sul”, tal como hoje é a formulação hegemônica, expressa na primeira citação deste artigo. Inclusive, tal formulação foi legitimada por meio de uma eleição direta em todo o estado, em que esta música foi escolhida como a mais representativa do MS por votação popular em 2001. A votação foi realizada por meio de urnas eletrônicas, cedidas pelo TRE. Em todo o estado, contou com a participação de 27.698 pessoas. A canção recebeu 12.112 votos (43,73\% do total) e venceu em 52 dos 77 municípios do MS. Em cidades como Aquidauana, Anastácio e Corumbá, por onde o trem passava, a votação nessa música passou dos $70 \%{ }^{22}$.

${ }^{21}$ GUIZZO, José Octávio. Op. cit., p. 27.

${ }^{22}$ RMT: "Trem do Pantanal é eleita a música de Mato Grosso do Sul”. In: RMT Online. Sítio na internet da Rede Matogrossense de Televisão. Disponível em: http://rmonline.globo.com/ms/. Acesso em: 29 mai 2007. 
É importante notar que o estado possui um hino oficial, com música de Radamés Gnattali e letra de Jorge Antonio Siufi e Otávio Gonçalves Gomes. No entanto, este hino, como se pode ver, não foi aceito pelos sul-mato-grossenses como representativo de sua identidade, sendo largamente desconhecido pela população. O desinteresse pelo hino oficial, imposto pelas elites dirigentes, foi tanto, que ele apenas foi gravado dezessete anos depois de instituído, na coletânea Mato Grosso do Som, de 199423. Esta situação de valorização social do "Trem do Pantanal" e de amplo desinteresse pelo hino do estado levou o próprio poder público a explorar em eventos oficiais as mesmas conexões entre essa música e a identidade do sul-mato-grossense. Um exemplo desta instrumentalização se pode ver na seguinte notícia, sobre o lançamento, no MS, da XIV edição dos Jogos Abertos Brasileiros de 2005:

Um público estimado em cinco mil pessoas, incluindo atletas das delegações dos estados de Mato Grosso, Minas Gerais, Paraná, Rio de Janeiro, Rio Grande do Sul, Santa Catarina, São Paulo e Mato Grosso do Sul, autoridades e comunidade esportiva presenciaram o acendimento da pira olímpica, [e] várias apresentações (...) musicais (como a do coral da Assembléia Legislativa de Mato Grosso do Sul, que interpretou o Hino Nacional Brasileiro e a música Trem do Pantanal). Em nome do governador Zeca do PT, o secretário Dirceu Lanzarini entregou flores à prefeita Maria da Saudade Medeiros Braga (PSB), de Nova Friburgo (RJ) (...) Estiveram presentes na solenidade de abertura os secretários Dirceu Lanzarini (Juventude e do Esporte e Lazer) e Matias Gonsales (Saúde); os deputados estaduais Antônio Carlos Arroyo (PL), Paulo Corrêa (PL) e Pedro Teruel (PT); além do representante da superintendência do Banco do Brasil (parceiro dos jogos) em Mato Grosso do Sul, João Santana; o representante da Setass (Secretaria de estado de Trabalho, Assistência Social e Economia Solidária), Afonso Areco; (...) o diretor de esportes do estado do Paraná, Lester Pinheiro; (...) a prefeita de Nova Friburgo, Maria da Saudade Medeiros Braga, e outras autoridades. ${ }^{24}$

Fica confirmada, então, a aceitação, por parte inclusive das elites decisórias, de "Trem do Pantanal" como um "hino de Mato Grosso do Sul”, por sua

\footnotetext{
${ }^{23}$ NACASATO, Odon. Depoimento pessoal concedido ao autor.09 jan. 2009.

${ }^{24}$ AGÊNCIA POPULAR DE NOTÍCIAS. Governo do Estado de Mato Grosso do Sul. "Começam oficialmente em MS os Jogos Abertos Brasileiros”. JUNQUEIRA, Vevila. 21.05.2005. Disponível em: http://www.sejel.ms.gov.br/canal.htm?canal=24\&meio=materia\&ma_id=457>. Acesso em: 30/09/2006.
} 
execução, em cerimônia oficial, ao lado do Hino Nacional Brasileiro. Portanto, por um processo complexo e problemático, cujos pontos principais foram assinalados, "Trem do Pantanal", como representante e parte da MLC atinge, finalmente, a posição de "hino de Mato Grosso do Sul" por iniciativa da população, que, no mesmo movimento, expressa seu desinteresse pelo hino oficial como símbolo do MS. No entanto, o movimento não pairaria soberano sobre este cenário de contradições.

Nove anos depois da edição do Festival que trouxe à cena urbana de Campo Grande uma nova experiência musical que buscava hibridizar o rural e o urbano, o arcaico e o moderno, ocorre a divisão - ou criação - do estado (em 1977). Neste momento, as elites agrárias ascendem ao poder executivo e sentem, elas mesmas, a necessidade de superar esta dicotomia, elaborando um discurso de integração regional. Isso era necessário, para que se conseguisse a adesão de todo estado ao projeto divisionista: afinal, seria impossível justificar a divisão da unidade federativa sem a proclamação de vantagens inequívocas para toda a população, seja da capital, seja do interior, independente de sua classe social. Assim, os discursos verbais se encarregaram de propor essa integração, ressaltando os benefícios que adviriam ao novo estado dividido. Segundo esses discursos, os recursos gerados pela vitalidade econômica propiciada pela pecuária sulista deixariam de ser continuamente drenados, de maneira supostamente parasítica, para a sustentação do norte, passando a promover o desenvolvimento do sul.

No entanto, faltava ainda um elemento fundamental para este projeto de integração: uma produção cultural significativa do próprio estado. Algo que reforçasse um discurso de unificação com os poderosos recursos de mobilização emocional proporcionados pela música. No caso, a unificação cultural e política de toda a região repentinamente pertencente ao estado de Mato Grosso do Sul, e que lhe desse um senso de identidade. Mas que, ao mesmo tempo, fosse capaz de expressar a sofisticação cultural, o cosmopolitismo e desenvolvimentismo exibidos como marcas da diferença e liderança das elites dirigentes de Campo Grande. E que estabelecesse uma clara hierarquia entre capital e interior, classes médias e subalternas.

Esta produção viria a ser a Música do Litoral Central. A MLC foi a primeira produção cultural do sul do então Mato Grosso que vinha realizando, com propósitos críticos, uma reflexão sobre a urbanização de Campo Grande a partir de sua 
posição periférica no interior do Brasil e na América Platina. Para este propósito, sintetizava a experiência urbana dos grandes centros nacionais e globais às influências pantaneiras, caipiras e latino-americanas, constituintes do interior do estado e, em menor escala, do cotidiano de Campo Grande. Buscava, entretanto, um relato fragmentário, que priorizava Campo Grande em relação ao interior, uma vez que, devido a sua dependência direta da economia agrária, o restante do estado estaria estruturalmente impedido de se integrar à proposta modernizante partida de Campo Grande.

Como evidência do caráter fragmentário da MLC, sua suposta representatividade após a divisão, defendida pela imprensa, discursos oficiais e não-oficiais, artistas e intelectuais, não é, entretanto, assumida por todos os segmentos sociais do estado. Os setores populares, mesmo da cidade de Campo Grande, parecem identificar-se mais com as duplas sertanejas pop, de sucesso atual (em oposição às duplas caipiras e sertanejas mais antigas) e com o fenômeno dos modernos grupos de baile sertanejos-axé music (os chamados "baileiros"). Por sua vez, na atualidade, a maior parte dos jovens das classes médias, mesmo de Campo Grande, parecem definir-se musicalmente por uma infinidade de gêneros musicais nacionais e internacionais, entre os quais figura com destaque, mais uma vez, o fenômeno sertanejo pop, em especial os baileiros e o dito "sertanejo universitário". Isto é relevante para caracterizar o discurso musical da MLC vis-à-vis discursos ideológicos e disputas por poder, passados alguns anos após a divisão do estado.

Embora a MLC consista, muitas vezes, de canções com forte inspiração musical caipira e paraguaia, nunca se confunde com uma sensibilidade popular propriamente dita. De maneira geral, evita o canto a duas vozes e o histrionismo característico dessas músicas. Quanto aos padrões de emissão, volta-se para aqueles mais assemelhados à ausência de grandiloquência da bossa nova, da Jovem Guarda e da Tropicália, embora também percorra, ocasionalmente, todo o arco que vai daí ao dramático. Com relação às letras, tendem a ser bastante elaboradas, à maneira da MPB, e mesmo em seus momentos mais despretensiosos, não se confundem com o universo cultural dos trabalhadores rurais. Com isso, a MLC se afasta da comunicabilidade direta buscada pelos apreciadores da música sertaneja pop contemporânea, resultando em uma popularidade bastante pequena dessa música no restante do estado. 
Este perfil da MLC coloca-a como porta-voz da procura, por parte das classes médias urbanas nas décadas de 1960 e 1970, de um caminho que levasse à urbanização e desenvolvimento da cidade e à modernização de suas estruturas sociais. As vicissitudes deste projeto, em que forças urbanas evidenciam certa simbiose e mesmo dependência da economia rural, mas, ao mesmo tempo, buscam questionar as bases ideológicas produzidas por esta economia - que são hegemônicas no restante do estado - , são, em grande parte, as vicissitudes da MLC.

Marcado por estas contradições, o movimento viria a ser parcialmente cooptado pelas classes dirigentes a partir da divisão. Conveniente aos seus propósitos, a MLC cumpria a contento a missão de unir elementos tradicionalmente entendidos como definidores da fisionomia cultural do estado a técnicas e procedimentos sofisticados e avançados para a época. Assim procedendo, realizava uma síntese entre tradição e modernidade, traduzindo em música e letra uma narrativa desenvolvimentista liderada pelas elites decisórias da capital que, concomitantemente, integrava o interior do estado a seu projeto. Neste sentido, foi um poderoso auxílio para a invenção de tradições ${ }^{25}$ convenientes aos detentores do poder na nova estrutura governamental e política.

Como resultado da divisão do estado, muitos mato-grossenses se tornaram mato-grossenses do sul, literalmente da noite para o dia, sem serem consultados, por um ato da ditadura. A MLC foi procurada para fornecer certezas fundadoras para pacificar as grandes inquietações, incertezas e indefinições produzidas por este ato. No entanto, apesar de, na década de 1980, conseguir gozar de uma visibilidade inédita até então, a década de 1990 afastou do movimento o público mais expressivo da capital - que, devido ao intenso movimento migratório, já era outro, ligado a outras realidades e grandemente desconhecedor e desinteressado dos processos singulares locais. Os dados do IBGE explicitam a amplitude desta transformação demográfica: em 1970, a população urbana de Campo Grande era de 131.110 habitantes; em 1980, ano seguinte à efetiva implantação da capital, 283.653, mais do que o dobro, portanto. Em 2009, a população da cidade era de 755.107 habitantes ${ }^{26}$.

${ }^{25}$ HOBSBAWM, Eric J., RANGER, Terence O. A invenção das tradições. Trad. Celina Cardim Cavalcante. Rio de Janeiro: Paz e Terra, 1984.

${ }^{26}$ IBGE. Campo Grande, MS: estimative da população, 2009. In: IBGE Cidades. Disponível em: $<$ http://www.ibge.gov.br/cidadesat/topwindow.hum?1> Acesso em: 09 fev.2010. 
Com a grande quantidade de pessoas recém-chegadas, desvinculadas do processo de procura singular que se processava na cidade de Campo Grande até o advento da divisão, e do qual fazia parte a MLC, passaram a predominar duas configurações. De um lado, os recém-chegados de todas as classes sociais - inclusive as classes médias e altas - , vinculados às culturas populares de origem rural do Centro-Sul como um todo, formaram um considerável mercado consumidor para estes produtos, estimulando o fortalecimento e popularização de duplas de "sertanejo universitário" e os baileiros. De outro, os identificados unicamente com a cultura urbana de suas cidades de origem e dos grandes centros brasileiros, propensos a recusar qualquer referência ao mundo rural e à situação do estado no cruzamento transfronteiriço da América Platina, tornaram-se críticos da MLC, vista como representante da ideologia agrária, largamente responsabilizada pelo atraso na região. De uma maneira ou de outra, o processo de reflexão sobre a modernização da cidade e do estado a partir da situação peculiar de ambos, com sua problemática herança agropecuária, no interior do hemisfério sul, tendo como vizinhos Paraguai e Bolívia, com sua configuração étnica e histórica singular, foi interrompido.

Embora o desenvolvimento do interior fosse incluído nas preocupações dos compositores, devendo supostamente se dar a partir do modelo que se estava gestando em Campo Grande, esta pretensão apenas traía sua matriz idealista. Comprometida diretamente com relações de produção agrárias, esta parte do estado não poderia partilhar da cultura urbana que aqueles procuravam desenvolver. Dessa maneira, a MLC não poderia obter apoio político e econômico do interior, cuja recepção largamente ignorou o movimento.

Desconsiderando esta dialética, sem apoio econômico ou político do interior, os compositores da MLC terminaram por ser cooptados para o projeto hegemônico das elites agrárias, quando ocorre a divisão e elas ascendem ao controle do aparelho ideológico do Estado. Tal apoio seria materialmente impossível de obter, de qualquer modo, para um projeto elitista que visava o alinhamento cultural a um perfil urbano e cosmopolita, em um estado com diminuta classe média capaz de se identificar com e sustentar um tal projeto. A direção apontada claramente pelas elites que ascenderam ao poder após a divisão, que conseguiram envolver a sociedade como um todo em seu projeto, articulou-se com as legítimas preocupações desses compositores e de outros atores sociais. Que eram as de levar em consideração sua problemática realidade rural, ecológica e latino- 
-americana, para uma concepção singular do viver urbano local. Assim procedendo, desvirtuou-as em favor de um sentimentalismo bucólico, exoticizante, primitivista e marcado pelo desejo de autenticidade.

Com isso, a MLC passa a experimentar baixa popularidade também na capital (uma vez que nunca havia sido realmente popular no interior). No entanto, apesar de não usufruir de popularidade, continua possuindo prestígio, sendo referida por diversos membros da sociedade campo-grandense, de diversas classes sociais, como representativa da cultura do estado, mesmo que não seja a música de suas preferências ou a que escutam habitualmente. Com relação a esta discrepância entre popularidade e prestígio, foi possível construí-la como correlata à falta de identificação das camadas populares do interior, e mesmo da capital, com o universo cultural urbano, cosmopolita, de vanguarda, proposto pela MLC. No entanto, o fato de que essa música se fez associar ao projeto político divisionista das elites dominantes da cidade de Campo Grande, lhe conferiu o prestígio de que goza até o momento, em certos círculos, apesar de sua pequena popularidade. Em contrapartida, sofre a recusa de certos setores urbanos justamente em decorrência dessa associação, que lhe fez assumir características regressivas, nostálgicas, bucólicas, oficialescas e nativistas.

Apesar de seus impasses, a utopia proposta pela MLC atende ao propósito de uma reflexão sobre "a fronteira onde o Brasil foi Paraguai" e mais além - o continente em que vivemos e que tanto desconhecemos. Esta reflexão evidencia conflitos locais, entre pecuaristas, profissionais da área de serviços, compositores, intérpretes, jornalistas e intelectuais, que se articulam a conflitos nacionais e globais. No momento atual, as oligarquias rurais estão dando lugar a oligarquias urbanas, como comprovam os índices do PIB no estado. Estas transformações são resultado não apenas de escolhas locais, mas de pressões globais, com a apropriação do meio ambiente representada pelo ecobusiness figurando com destaque. No entanto, esta situação não impede a eficácia da participação local, da mesma maneira que, como vimos, a música participou, com um papel ativo não como mero reflexo da atividade econômica - do processo de construção do capital e de sua transformação em Mato Grosso do Sul. A Música do Litoral Central se oferece como exemplo, assim, de como as resistências e sucessos relativos dessas resistências são eficazes como forma de evitar o fatalismo e a descrença na possibilidade de transformação do modo de produção. 